\title{
Applying Social-Gamification for Interactive Learning in Tuberculosis Education
}

\author{
Dhana Sudana ${ }^{1}$, Andi W.R. Emanuel ${ }^{2 *}$, Suyoto ${ }^{3}$ \\ Universitas Atma Jaya Yogyakarta \\ Sleman, Indonesia 55281
}

\author{
Ardorisye S. Fornia ${ }^{4}$ \\ PKU Muhamadiyah Yogyakarta Hospital \\ Yogyakarta, Indonesia 55122
}

\begin{abstract}
There are several methods of education for tuberculosis, and one of them is through the DOTS (Direct Observed Treatment Shortcourse) program. The management of tuberculosis education through the DOTS program is performed in clinics and hospitals only to patients and their families. The purpose of this study is to describe the development and testing of a prototype (social-game education) for interactive education for tuberculosis patients in particular and the general public. The data collection process is through direct observation of tuberculosis patients and health professionals (doctors, nurses, and DOTS health workers). Challenge the game in the prototype was provided with content that contained tuberculosis information that had been previously validated by a specialist. In addition to tuberculosis information as the main content, two important elements are making up this prototype, which are gamification and social media elements. In the game elements, this study adopted elements of the leaderboard, badge/achievement, challenge, and level. As for the third element, social media includes likes, comments, and shares. Prototype application testing was conducted on two participant groups $(\mathbf{N}=$ 48) consisting of 23 tuberculosis patients and 25 random participants. By using the user experience questionnaire (UEQ) technique, this research focuses on identifying the user's motivation in capturing compositional information as well as the clarity of the prototype. With a confidence interval of $5 \%(p=$ 0.05) per scale. The results indicate that participants have a high level of motivation towards the prototype; this is seen in the rating scale of stimulation with an average of 1.578. Likewise the effectiveness level of information in the rating scale of perspicuity has a mean of $\mathbf{1 . 2 2 4}$ also has a rate that is quite effective.
\end{abstract}

Keywords-Education; gamification; mobile application; social-media; tuberculosis

\section{INTRODUCTION}

Based on the WHO report in 2017, Indonesia is one of the countries with the highest number of tuberculosis sufferers in the world. Even tuberculosis infection is still the number one cause of death in Indonesia. The tuberculosis incidence rate in Indonesia is 395 per 100,000 population, and the death rate is 40 people per 100,000 per year [1]. Preventing transmission by optimizing tuberculosis case finding and healing is a program through DOTS (Direct Observed Treatment Shortcourse) [2]. Through the DOTS program [3][4], the method of prevention by detecting tuberculosis transmission among family members and those closest to the patient includes maximizing the tuberculosis education program. Actually, besides being able to support the prevention of tuberculosis, broad education about the disease can also reduce the unfortunate stigma of tuberculosis patients. In an all-digital era with a large community, mobile access can be an easy way in tuberculosis education widely, including through games and social media. Education through gamification methods [5] and social media methods [6] are proven to increase motivation and learning achievement.

Today's gaming applications continue to develop primarily as a means of education; even many gaming applications adopt elements of social media or social - gamification. The combination of social media elements in gamification gives the individual creating a profile or person and interacting with other users in each gameplay. Many educational institutions use the aspects of social media and games as a means of learning to motivate students and teachers alike [7]. Likewise, in the field of health, some elements of games and social media are used in various applications to help motivate patients undergoing therapy as well as stimulating a healthy lifestyle [8].

Based on the level of effectiveness of the role of games and social media in the world of education, this research focuses on the design of social-gamification content as a means of tuberculosis information and knowledge. Lung specialist doctors validate the social-games content to test the truth about tuberculosis educational content. Giving an achievement in the form of a badge or points to the player can motivate users in learning and explore the deeper aspects of education [9]. In contrast, the adoption of the elements like likes and comments contained in social media gives users a share of achievements to friends who are on the friend's list.

In this study, we designed a prototype of tuberculosis disease learning applications. Our specifics are adopting social media and utilizing elements of gamification. By using the elements of social media, such as sharing, liking, and commenting, and utilizing the two elements of gamification elements, namely the mechanical and dynamic elements. The focus of the evaluation is to identify two elements of effectiveness, namely participant motivation and understanding of prototype content, whose ultimate goal is education. This social-gamification prototype was tested on participants using the user experience questionnaire (UEQ) method [10]. We differentiate between the two participant populations to compare the effectiveness of TB education learning. In this study, we also tried to identify user reactions by analyzing participants' opinions.

\footnotetext{
*Corresponding Author
} 


\section{RELATED WORK}

There are several studies on social-gamification for tuberculosis education. A survey on tuberculosis education explains, in general, tuberculosis disease education uses a conventional approach through the DOTS (Direct Observed Treatment Shortcourse) program. In the DOTS program, the patient and the patient's family are given oral education to motivate tuberculosis patients and cope with drug withdrawal behavior [11]. But in the study of Lam, et al. in 2018 explained that education and care for tuberculosis patients could be done remotely with Video-DOTS [12]. Ilya et al. also demonstrate that distance education through online games provides more effective benefits because it can find out study time, number of social relationships, and get bonus game points [13].

Several previous studies have explained that more and more educational methods in the prevention of disease and health care through gamification methods [14][15]. Research by Hursen et al. in 2019, about the purpose of gamification in scientific education using mixed qualitative and quantitative data, showed positive results on student motivation [16]. In a study conducted by Dithmer et al. in 2016, proposed a prototype experiment to help heart patients undergo telerehabilitation using the Teledialog Method to encourage patients. Also, there is research on improving learning with the gamification method associated with social networking [17]. The implementation of gamification methods and social media is to increase student participation in learning for emergency medicine in the world of health [18]. The effect of the gamification learning model also shows a positive attitude towards groups of students due to learning [19].

Today there are many approaches through media games and also social media with several cases in the world of medicine and health as a means of education. Also, the use of social media applications and games today contributes to the use of mobile as a healthy lifestyle media [8]. The use of social media and games as a means of learning for motivating students in learning mathematics [7]. The use of social media in education on mobile applications has also proven able to reduce communication difficulties in college. The case study by Denizalp, et al., involved 30 teachers and 20 students for 12 weeks focusing on communication between students and teachers through social media. [20].

The study of Yen et al. in 2018 that the effects of games change a person's behavior in many ways, including education and activity [21]. Also, gamification is introduced to motivate someone [22][23]. In this research, it is assumed that the gamification method was quickly driving someone because the game element makes people feel given a challenge. The use of a prototype to motivate cardiac patients consists of several challenges of patient activity based on several elements of gamification; the results show that the level of each game builds motivation for heart patients [14]. Also, in a study explaining the use of gamification methods and elements of social media proved able to make a positive relationship between educational practices and enthusiasm and communication [24]. We also include references from the literature review that explain gamification refers to information systems designed to provide the same experience and motivation as games, and consequently, seek to influence user behavior [22]. Even a study that uses virtual games in recognizing objects around can have a good impact on early childhood [25]. In some studies, elements in games have been proven to have a positive impact on users. In the study of Wang et al. in 2017 explained that the influence of badge and game time plays an essential role in motivating students in mathematics in the form of interactive games [26].

A prototype application cannot be launched to the user without testing, both the system and the benefits of knowing interactive experiences between games and users [27]. In the study of Santoso et al. in 2016 explained the use of measuring tools developed from the user experience questionnaire (UEQ) to measure the experience of users of learning applications. [28]. The user experience questionnaire (UEQ) explains the identification of 6 crucial issues with user experience parameters in testing an app to find the application usability or prototype design that will be used to see if the model is useful in solving problems [29]. Also, research on the identification of expressions based on facial mimics as well as participant opinion, which is helpful to know the user's response directly and also as a benchmark to find out the lack of applications based on user opinion [16] [30].

As mentioned earlier, education about tuberculosis for tuberculosis patients through the DOTS program is vital as a preventative measure. However, mobile tuberculosis education is widely interactive and fun. It can support more interesting tuberculosis education programs. Although in the previous literature explained that there had been many uses of social media and gamification methods in the world of education and health, there has been no research analyzing both approaches for tuberculosis education. In this case, this research aims to find out the effectiveness of tuberculosis education widely using the social-gamification method.

\section{RESEARCH QUESTIONS}

Tuberculosis education using the methods implemented in the DOTS program prioritizes the delivery of information on tuberculosis to patients and their families. The doctor or health worker educates by conveying orally and persuasively to the patient, and the family or the person closest to the patient. From previous research studies in the last section, we found several things that can be used as a reference in this study. Our research questions refer to active learning methods through social media and gamification that can be done by patients and users widely. There are some of the objectives of the research question:

- How to model social-gamification for tuberculosis education based on mobile user interaction?

- Can social-gamification content help convey information about tuberculosis education?

- Does the tuberculosis education social-gamification mobile application have an impact on user reactions such as motivating users in educating tuberculosis? 


\section{METHOD AND MATERIAL}

This research is a type of development research by proposing a prototype of mobile application design for tuberculosis education using gamification that adopts elements of social media or social-gamification characteristics. The flow of this research stage is shown in Fig. 1.

From Fig. 1, there are three main stages of research. The first stage is the prototype pre-design stage; at this stage, we begin by direct observation of user needs in clinics (community Health centers/Puskesmas) and hospitals that treat patients with tuberculosis diagnoses. At this stage, we also identified prototype needs based on the principal elements of gamification and social media elements. In the next step, determine the Tuberculosis information that is needed part of the content of the prototype. The next stage is to build a prototype and test it. At this stage, the design is made based on the needs that have been identified at the pre-design phase. At this stage, participants are filling the form of testing based on the prototype to see the user's reaction to the application; several game scenarios are prepared at this stage [31]. The last step is the evaluation stage; we are giving out a questionnaire (UEQ) [10], opinion form, and observation of correspondent expressions. The results of this identification are then evaluated and analyzed.

\section{A. Studi Population}

To make the application run properly requires participant testing. This participant consists of participant par-prototype and post-prototype. We involve doctors, health workers, and voluntary participants. Total $\mathrm{N}=15$ for pre-prototype particles. As for the post-prototype, we involved 48 participants, consisting of participants with tuberculosis and general participants. These participants were distributed in 2 clinics (Puskesmas) and two hospitals in Yogyakarta and Central Java. Tuberculosis participants were 23 participants $(\mathrm{N}=23)$, and this general participant included the families of tuberculosis patients or those who knew tuberculosis patients were 25 people $(\mathrm{N}=25)$. In addition to participants in clinics (Puskemas) and hospitals, we also include participants who come from the tuberculosis surveillance community on social media contacted online.

\section{B. Data Collection}

Data collection is part of the observation phase is divided into two parts: literature study and field study. In literature studies, we look for sources from a variety of previous studies related to this research. Among recommended journals and also studies through books about tuberculosis. Whereas in the field study, we observed directly with short interviews in clinics and hospitals, of tuberculosis patients, patients' families, health workers, and doctors. At this stage, we also take the primary supporting data as the content of the content that will be created.

In Fig. 2 shows one of the supporting data Tuberculosis information released by the health department. Tuberculosis information brochures are given to tuberculosis patients or as public information material. This brochure data and health information are then validated by the doctor and become the prototype information content. The content element is the most important because it relates to the purpose of research, namely tuberculosis education.

\section{Determine Element}

In developing this prototype, we selected several essential elements as design input. The determination of the specification of gamification design requirements follows the flow according to the needs analysis, which also includes social media elements. And identify the first game designs used and user requirements for the mobile application to be created [14] [30]. The two principals are as follows:

- Gamification elements include challenge elements, levels, badges, awards, and points, and leaderboard. The use of these elements is intended to add motivation to each game. Besides, each level is given a duration of play so that users are encouraged to continue playing.

- Social media elements, for this element, we include aspects like and share. Share in the prototype that was built; there are two objectives. One to share points in quizzes and tasks, and to share ranking status.

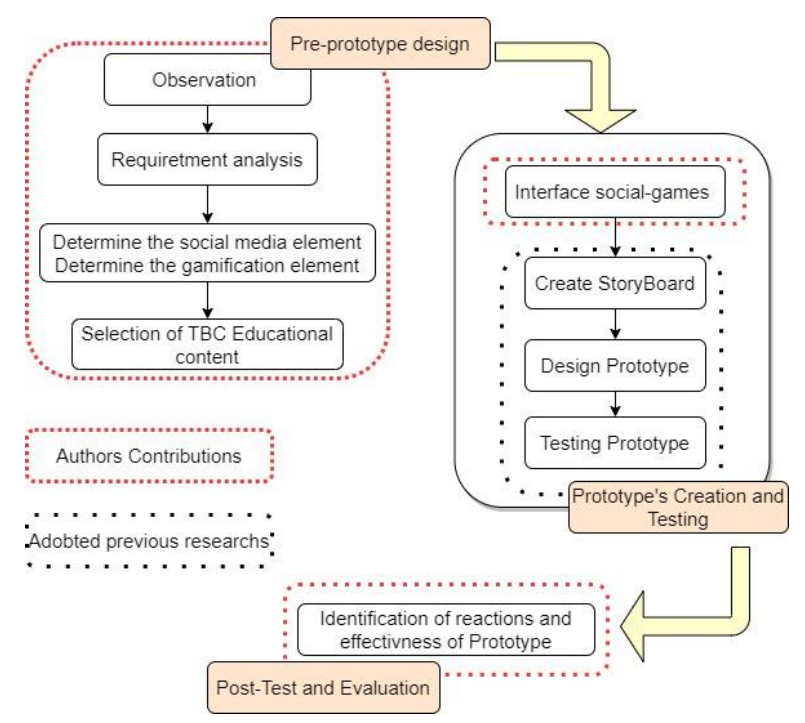

Fig. 1. Research Design.

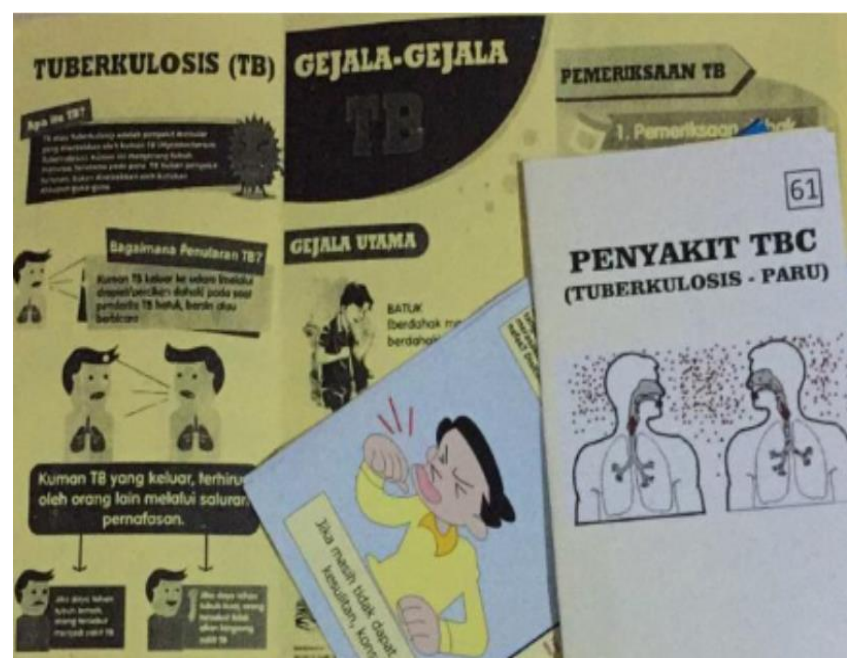

Fig. 2. Tuberculosis Brochures. 


\section{Requirement Analysis}

To facilitate the needs of the system, we conducted semistructured interviews before designing the prototype. And provide a form containing input design application features that will be made to the participant $(\mathrm{N}=15)$. The purpose of this form is to determine the user's needs for application features. Participants from the doctors, health workers, and random patients selected can provide input to the system that will be created directly through this form.

TABLE. I. FEATURE AND DESCRIPTION

\begin{tabular}{|l|l|}
\hline Feature & Description \\
\hline Announcements & $\begin{array}{l}\text { Opening the games menu to the user, and the first hint is } \\
\text { game games. }\end{array}$ \\
\hline Challenges & In the form of a quiz with tuberculosis information content. \\
\hline Quiz & Other users can share quiz completion/challenge menus. \\
\hline Content & $\begin{array}{l}\text { The challenge is in the form of a quiz with tuberculosis } \\
\text { information content }\end{array}$ \\
\hline Share & $\begin{array}{l}\text { Players can share the results of the game (achievement) } \\
\text { their progress on social media }\end{array}$ \\
\hline Profile & Players can change profile characters to avatars \\
\hline Task & $\begin{array}{l}\text { Completion menu about tasks consisting of activities } \\
\text { during treatment }\end{array}$ \\
\hline
\end{tabular}

Table I is the result of the analysis of features needed based on the form that was previously randomly distributed to patients and health workers-some of the main elements required as input with details in the table. The aim of the design prototype was following the objectives, as well as knowing the needs of users with the ultimate goal of delivering tuberculosis education interactively.

\section{RESUlT AND DiscUSSION}

To compare the performance of delivering tuberculosis educational content in the design of social-gamification applications, we prepared a game Hypothesis Scenario. One of the first scenery instruments for participant games is required to answer quizzes that are limited by backward. Each game will have a "share" help option where the player can use the help with a record of points that will be obtained only $50 \%$, and $50 \%$ is given by friends who help. Share can also be done to show achievements in the ranking board. Badge assignment and badge redemption are given if the player has completed a game with points that meet the required amount. The prototype of the social game mobile application can be seen in Fig. 3(a \& b) and Fig. 4(a \& b).

In Fig. 3(a) is one of the initial levels of games that contain quizzes with 300 points rewards. In each game, both the quiz and the player's task will be given a share option. While Fig. 3(b) is a screen that shows a list of friends' contacts. Players can choose one friend to help get useful answers.

Fig. 4(a) shows answers from a friend, in the picture, shows the time the game continues to run backward, the goal is to provide motivation. While Fig. $4(\mathrm{~b})$ is a point achievement, it can be seen that the points earned are divided into 150 points. Besides that, in each final answer, there is information about the response that provides education following the target of tuberculosis education.

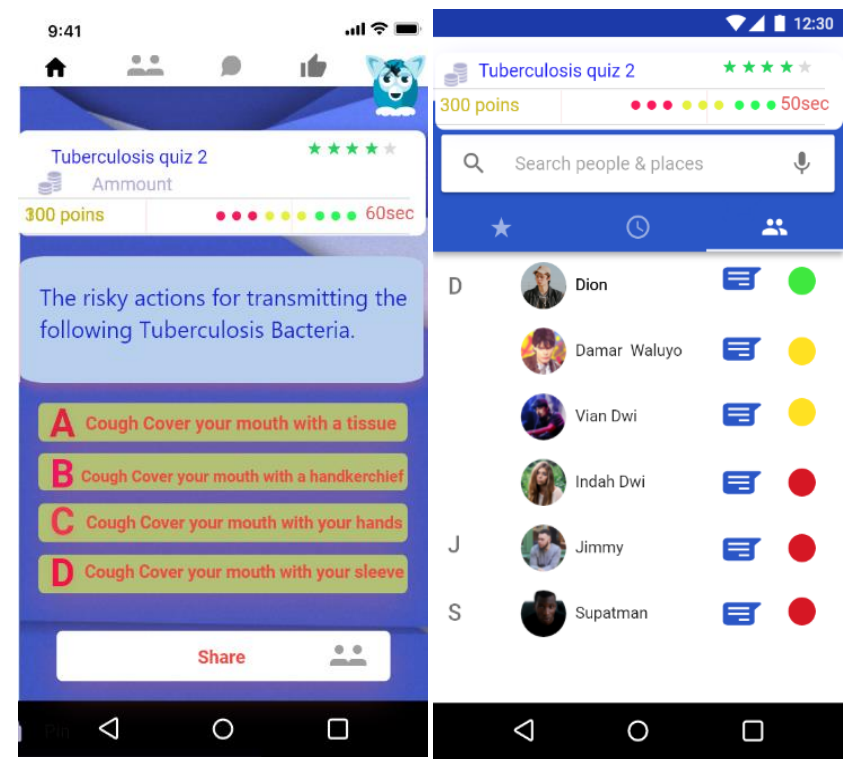

Fig. 3. Interface Application (3a \& 3b).

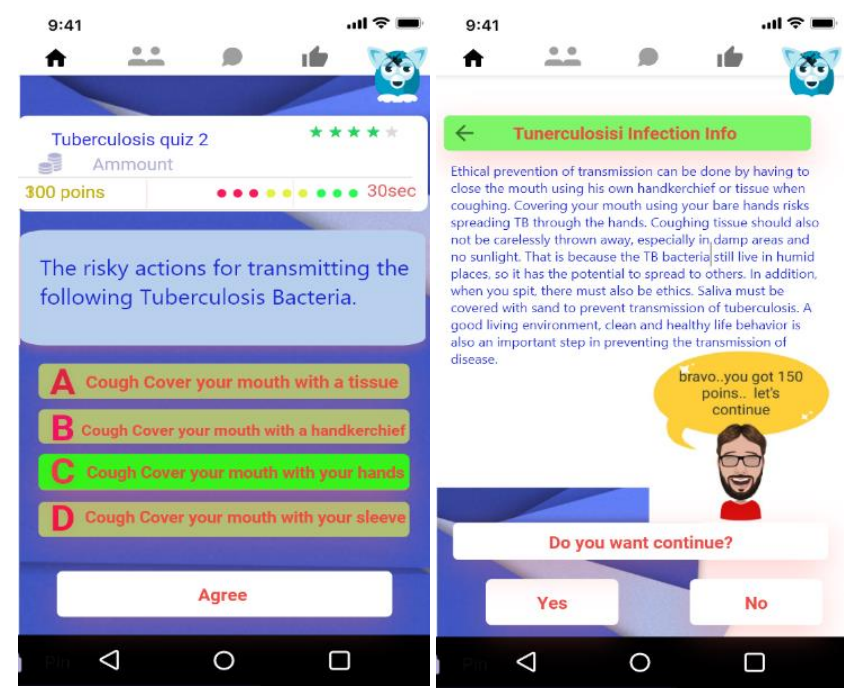

Fig. 4. Interface Application (4a \& 4d).

\section{A. User Experiment}

In addition to content that contains information about tuberculosis to get an interactive education, we believe that through games and social participants will be more motivated. The use of elements in games such as levels, achievement points, and badges) triggers enthusiastic participants in finding information about tuberculosis. To see an acceptable prototype application, we propose a user experience testing scheme. Testing is done on voluntary participants $\mathrm{N}=48$. During the test, we observed user behavior, especially facial expressions. In this test, we provide two simple scenarios for players.

- First Scenario, players perform quiz challenges and do tasks in the game without the help of "sharing".

- The second player's scenario is allowed to take share options to friends on the friends' list. 
The results obtained, many participants who could not answer the quiz and complete the task without the help of shares, especially the general participants. While in the second scenario, many participants take the risk of answering quiz and task challenges by asking in the share options even though the answers are not always correct. From the observations of many participants with tuberculosis conditions who are not confused with the material content. Facial expressions tend to be confident in being able to answer, in contrast to most general participants. In Fig. 4, the testing process in several clinics and hospitals has a DOTS corner.

Fig. 5 shows some participants, consisting of tuberculosis patients and general participants, was testing the application. We do prototype testing to the participant by prioritizing the leading participant, namely the hypnotic tuberculosis condition. Also, participants with high-risk situations were exposed to tuberculosis bacteria in the second category, even though we included them in the general classification. The number of voluntary participants is $48(\mathrm{~N}=48)$. From the results of the prototype test using a user experiential questioner (UEQ) [10][28], we identified participant experience with six scales containing 26 items. From the application material that has been tested by the participant, we use Confidence intervals $(p=0.05)$ per scale to determine the measurement of the accuracy of each estimated average range. The smaller the confidence interval will be making higher accuracy of the estimate. The following are the results of user experience testing in Table II.

In Table II is the result of the questionnaire's answer to the testing of participant experience, with statistical calculations for the average scale and the average item. There are six rating scales in the user experience questioner, and our identification shows that the stimulation rating scale has the highest results with an average score of 1.578 . This stimulation rating scale has a composition of items such as valuable/inferior, boring/outgoing, not interesting/interesting, motivating/decreasing motivation. Overall the results of the user experience questioner, if viewed graphically, can be seen in the graft benchmarks in Fig. 6 .

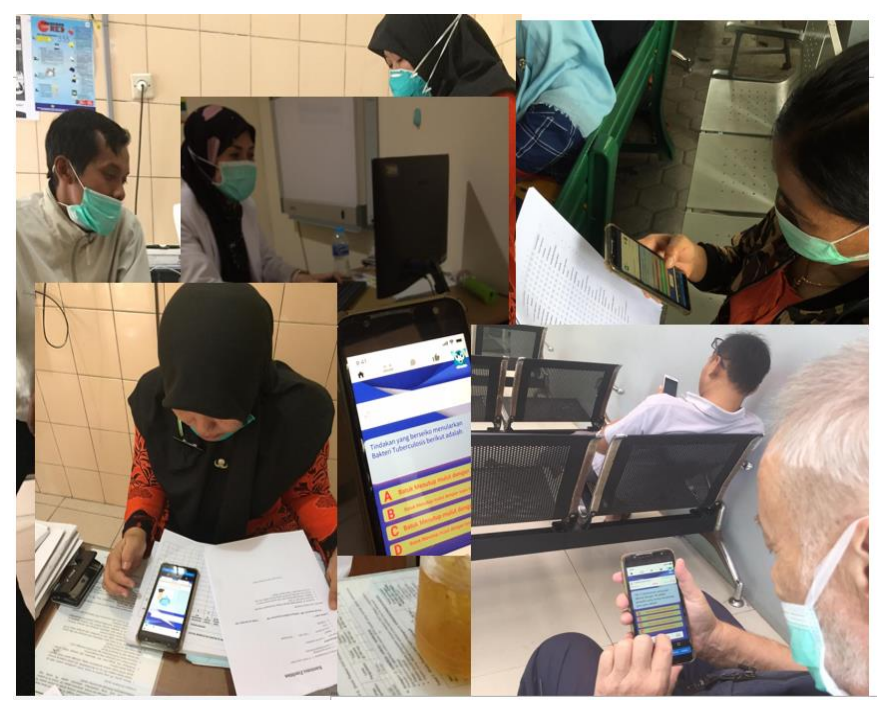

Fig. 5. Testing Application to Participants.
TABLE. II. CONFIDENCE INTERVAL RESULT

\begin{tabular}{|l|l|l|l|l|l|l|}
\hline Scale & Mean & SD & $\mathbf{N}$ & Confidence & \multicolumn{2}{|l|}{ Confidence interval } \\
\hline Attractiveness & 1.483 & 0.862 & 48 & 0.244 & 1.239 & 1.727 \\
\hline Perspicuity & 1.224 & 1.092 & 48 & 0.309 & 0.915 & 1.533 \\
\hline Efficiency & 1.125 & 1.038 & 48 & 0.294 & 0.831 & 1.419 \\
\hline Dependability & 1.083 & 0.876 & 48 & 0.248 & 0.836 & 1.331 \\
\hline Stimulation & 1.578 & 0.959 & 48 & 0.271 & 1.307 & 1.850 \\
\hline Novelty & 0.964 & 0.904 & 48 & 0.256 & 0.708 & 1.219 \\
\hline
\end{tabular}

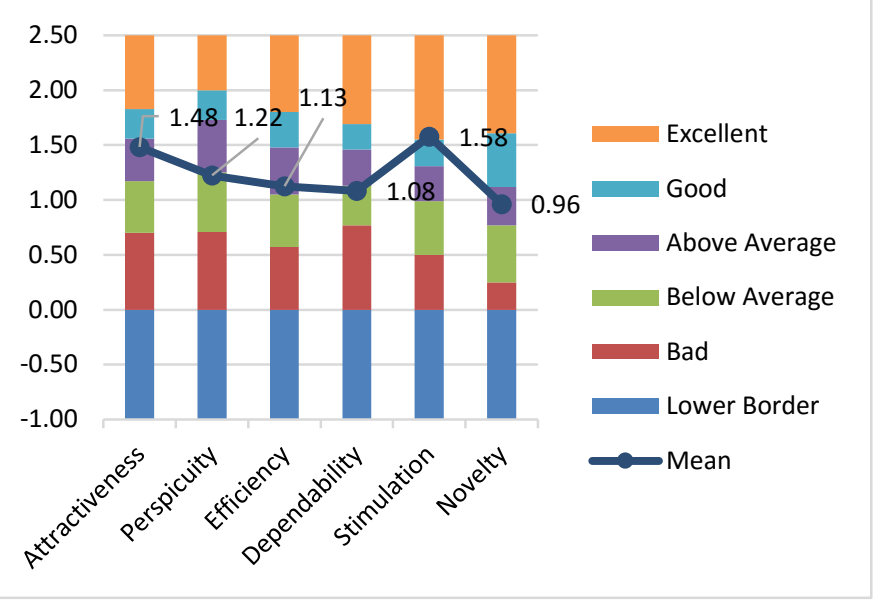

Fig. 6. Benchmark Graft All Participants.

Fig. 6 shows a comparison of the overall six rating scales. Of all items, our findings focus on identifying motivations that are compositionally stimulating items. Also on the graph can be seen the results of perspicuity with a mean score of 1.22, which is above average quality, being aware of the effectiveness of the product. Overall, the application is acceptable because most of the scores are above average, even though there is an item rating scale that is below average, namely the dependability rating scale with a mean value of 1.08. We identified that contributions to the dependability assessment scale were due to applications that sometimes did not respond as well. However, we are satisfied with the results obtained because they are under the research objectives of knowing the level of motivation and effectiveness that the application is going well.

\section{B. Participants Opinion}

In addition to interpreting the results of the user experience questionnaire statistically, to detect the prototype function is running well and as an evaluation of usability. To see the needs of the system in the future, we also provide a participant opinion form that presents insights into the experience of the participants during testing interviews and relevant quotes. To better know and define useful applications for tuberculosis education. There are two things that we describe, namely, components that are favoured by participants and elements that are not supported by participants. Due to the optional nature of the assessment carried out by 20 participants from 48 participants who are willing to provide direct evaluation and opinion. The results of identifying participant opinions are shown in Table III. 
Based on Table III, we evaluate the opinions of 20 participants who are part of the voluntary participant $\mathrm{N}=48$. Some opinions about component features can be obtained; it appears that the component that participant likes is the function and usefulness of nine people, and no one dislikes it. The contribution of this component, according to participants, because the social-gamification content has educational content that can be useful, whereas the participant that is not liked is another component item with a total of seven participants. However, the second component that is not liked is the application response, with the number of six participants. Here are some participant's opinions after feeling the experience test on the application.

C2: "The content presented is exciting and easy to understand; first, I doubt the information about tuberculosis can be used as a game" (like).

C1: "Overall, this application can be used, but does not respond quickly. What I like is there is a share option, this motivates me to see what it says" (like).

C5: "hmmm, the timer at the task challenge is too fast. Only 60 seconds, I did not think, especially I do not know much about tuberculosis" (dislike).

C4: "the application is loading a long time when I choose the answer the system does not run quickly" (dislike).

C2: "I like the contents of the information; in the end, the answers are given information in detail. Even though I answered wrongly, this is very educative. I think this can make entertainment and information for everyone" (like).

C2: "I have extra-pulmonary tuberculosis, and I feel this kind of interactive information is very useful, maybe it can be a daily challenge. The data is helpful for tuberculosis sufferers who are undergoing treatment" (like).

In the participant's opinion, it can be seen that the majority of participants received the prototype positively. We identified several significant sentences, especially positive opinions. Some of the words in the participant's affirmative sentences were delivered, such as "very interesting," "motivating," "interactive," "educative," and so on. Also, we identified several opinions that tended to be negative, and this was primarily aimed at applications. Some negative sentences that we can identify, such as the use of the words "confuse" and "long loading". From this input of participant opinion, we can also find out and improve applications in future research.

TABLE. III. COMPONENTS OPINIONS FOR PARTICIPANTS

\begin{tabular}{|l|l|l|}
\hline \multirow{2}{*}{ Components } & \multicolumn{2}{|l|}{ Frequency } \\
\cline { 2 - 3 } & Like & Dislike \\
\hline (C1) Games desain (in general) & 3 & 2 \\
\hline (C2) Content & 5 & 0 \\
\hline (C3) Function/useful & 9 & 0 \\
\hline (C4) Timer to play & 0 & 3 \\
\hline (C5) App respond & 0 & 6 \\
\hline (C6) Etc & 3 & 7 \\
\hline
\end{tabular}

\section{Discussion}

In general, from the experience test from $\mathrm{N}=47$, participants consisting of N1 (participant with tuberculosis conditions) went well. Although there is a rating scale that has a rate below average in UEQ benchmark, the items in the Dependability rating scale, which include unpredictable/ predictable, obstructive/supportive, secure/not secure, meet expectations/does not meet expectations items, indicate that an application cannot be separated from attention in terms of security, predictions, and application interactions towards users. Besides the app, we also find indications in terms of participant population that need to be discussed. In this study, we obtained voluntary participants of $\mathrm{N}=48$, which consisted of 23 participants with a tuberculosis diagnosis of 25 general participants. The results of the answers to these two participant groups identified interesting findings to discuss. The following is a visualization of the comparison of the twoclass categories seen in the comparison of scale means diagram Fig. 7.

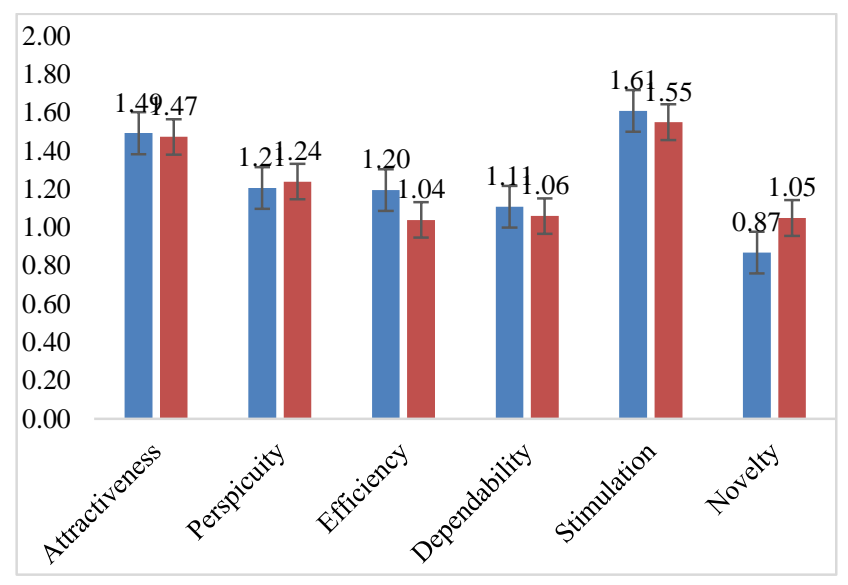

Fig. 7. Comparison of Scale Seans.

Fig. 7 shows a diagram containing a comparison of the results of participant answers. We group tuberculosis and general participant participants. There is not much difference in contrast between users with indications of Tuberculosis and typical participants. However, in some items, it appears that voluntary participants with a hint of tuberculosis are more enthusiastic compared to general participants. Of the six grading scales, four grading scales address participants with tuberculosis having higher outcomes than the general participant, namely for the rating scale of attractiveness, efficiency, dependability, and stimulation. Whereas the rating scale for perspicuity and novelty for general patients is larger. But overall, there were no significant differences in all the user experience questioner (UEQ) rating scales.

\section{CONCLUSION}

Based on our findings in the previous section, we conclude that by adopting social media and gamification into tuberculosis education on a mobile basis, the delivery of information is more effective. The results obtained indicate that the level of user acceptance in the application is quite good. Using UEQ tools, we can identify user responses and find two essential notes, namely: 
1) An assessment of the reactions of all participants. On the six UEQ ranking scales, the stimulation ranking scale has an excellent score of 1.58. Where in the stimulation assessment range, there are interesting and motivating assessment items. These findings indicate that the new and interactive education system is preferred by users and stimulates both in terms of TB education content and application features. While the attractiveness, perspective, efficiency, and novelty rating scales have an above-average rating, only the dependency rating scale has a below-average rating with a score of 1.08 .

2) Based on the comparative assessment of the two participant populations, we note that there are no significant differences on the general rating scale. From the attractiveness, rating scale show that participants with tuberculosis condition have a comparison score above the general participant of 1.49 versus 1.47 . While stimulation is 1.61 versus 1.55 , this proves TB participants are more interested in using prototypes.

In addition to identifying statistically through the UEQ tool, we also evaluate input from participants' opinions. This opinion can be used as a reference for future studies. In future research, the use of virtual reality in daily challenges that adopt TBC treatment activities and patient activities in the DOTS program as a form of further education and assistance for $\mathrm{TBC}$ patients.

\section{REFERENCES}

[1] "Global Tuberculosis Report 2017," 2017.

[2] G. Gebrezgabiher, G. Romha, E. Ejeta, G. Asebe, E. Zemene, and G. Ameni, "Treatment outcome of tuberculosis patients under directly observed treatment short course and factors affecting outcome in southern Ethiopia: A five-year retrospective study," PLoS One, vol. 11, no. 2, pp. 1-10, 2016.

[3] A. Probandari et al., "The path to impact of operational research on tuberculosis control policies and practices in Indonesia," Glob. Health Action, vol. 9, no. 1, 2016.

[4] I. Wayan Gede Artawan Eka Putra et al., "The implementation of early detection in tuberculosis contact investigation to improve case finding," J. Epidemiol. Glob. Health, vol. 9, no. 3, pp. 191-197, 2019.

[5] C. Maican, R. Lixandroiu, and C. Constantin, "Interactivia.ro - A study of a gamification framework using zero-cost tools," Comput. Human Behav., vol. 61, pp. 186-197, 2016.

[6] A. M. Price, K. Devis, G. LeMoine, S. Crouch, N. South, and R. Hossain, "First year nursing students use of social media within education: Results of a survey," Nurse Educ. Today, vol. 61, pp. 70-76, 2018.

[7] P. Juric, M. B. Bakaric, and M. Matetic, "Design and implementation of anonymized social network-based mobile game system for learning mathematics," Int. J. Emerg. Technol. Learn., vol. 13, no. 12, pp. 83-98, 2018.

[8] M. M. Nour, A. S. Rouf, and M. Allman-Farinelli, "Exploring young adult perspectives on the use of gamification and social media in a smartphone platform for improving vegetable intake," Appetite, vol. 120, pp. 547-556, 2018.

[9] L. Hakulinen, T. Auvinen, and A. Korhonen, "The effect of achievement badges on students' behavior: An empirical study in a university-levell computer science course," Int. J. Emerg. Technol. Learn., vol. 10, no. 1, pp. 18-29, 2015.

[10] M. Schrepp and A. Hinderks, "Design, User Experience, and Usability. Theories, Methods, and Tools for Designing the User Experience," vol. 8517 , no. June, 2014.
[11] A. Surya et al., "Quality tuberculosis care in Indonesia: Using patient pathway analysis to optimize public-private collaboration," J. Infect. Dis., vol. 216, no. suppl_7, pp. S724-S732, Nov. 2017.

[12] C. K. Lam, K. M. G. Pilote, A. Haque, J. Burzynski, C. Chuck, and M. Macaraig, "Using video technology to increase treatment completion for patients with latent tuberculosis infection on 3-month isoniazid and rifapentine: An implementation study," J. Med. Internet Res., vol. 20, no. $11,2018$.

[13] I. V., E. Nikulchev, A. A., and A. Y., "Study of Gamification Effectiveness in Online e-Learning Systems," Int. J. Adv. Comput. Sci. Appl., vol. 6, no. 2, pp. 71-77, 2015.

[14] M. Dithmer et al., “"The heart game': using gamification as part of a telerehabilitation program for heart patients," Games Health J., vol. 5, no. 1, pp. 27-33, 2016.

[15] R. Garett and S. D. Young, "Health care gamification: A study of game mechanics and elements," Technol. Knowl. Learn., pp. 1-13, 2018.

[16] C. Hursen and C. Bas, "Use of gamification applications in science education," Int. J. Emerg. Technol. Learn., vol. 14, no.1, pp. 4-23, 2019.

[17] A. M. Toda, R. M. C. do Carmo, A. P. da Silva, I. I. Bittencourt, and S. Isotani, "An approach for planning and deploying gamification concepts with social networks within educational contexts," Int. J. Inf. Manage., vol. 46, no. May, pp. 294-303, 2019.

[18] T. de A. G. Grangeia, B. de Jorge, D. Cecílio-Fernandes, R. A. Tio, and M. A. de Carvalho-Filho, "Learn+fun! Social media and gamification sum up to foster a community of practice during an emergency medicine rotation," Heal. Prof. Educ., pp. 1-15, 2018.

[19] I. Varannai, P. Sasvari, and A. Urbanovics, "The Use of Gamification in Higher Education: An Empirical Study," Int. J. Adv. Comput. Sci. Appl., vol. 8, no. 10, pp. 1-6, 2017.

[20] F. O. Hasan Denizalp, "Determination of student opinions on usage of social media and mobile tools in student-teacher, student-student communication,” Int. J. Emerg. Technol. Learn., vol. 14, no. 22, pp. 1928, 2019.

[21] B. T. H. Yen, C. Mulley, and M. Burke, "Gamification in transport interventions: Another way to improve travel behavioural change," Cities, vol. 85, no. January, pp. 140-149, 2019.

[22] J. Koivisto and J. Hamari, "The rise of motivational information systems: A review of gamification research," Int. J. Inf. Manage., vol. 45, no. July 2018, pp. 191-210, 2019.

[23] C. N. De Freitas, "Lean-based enterprise gamification: Realization of effective gamification in an enterprise context," pp. 1-48, 2015.

[24] G. Aydin, "Adoption of Gamified Systems," Int. J. Online Mark., vol. 5, no. 3, pp. 18-37, 2015.

[25] N. Kristianti, S. Niwayan Purnawati, and Suyoto, "Virtual education with puzzle games for early childhood: A study of Indonesia," Int. J. Eng. Pedagog., vol. 8, no. 2, pp. 14-22, 2018.

[26] F. Wang, Y. Wang, and X. Hu1, "Gamification teaching reform for higher vocational education in china: A case study on layout and management of distribution center," Int. J. Emerg. Technol. Learn., vol. 12, no. 9, pp. 130-144, 2017.

[27] M. Gonzalez-Salazar, H. Mitre-Hernandez, and C. Lara-Alvarez, "Method for Game Development Driven by User-eXperience: a Study of Rework, Productivity and Complexity of Use," Int. J. Adv. Comput. Sci. Appl., vol. 8, no. 2, pp. 394-402, 2017.

[28] H. B. Santoso, M. Schrepp, R. Yugo Kartono Isal, A. Y. Utomo, and B. Priyogi, "Measuring user experience of the student-centered E-learning environment," J. Educ. Online, vol. 13, no. 1, pp. 1-79, 2016.

[29] C. Maitland et al., "Measuring the capacity of active video games for social interaction: The Social Interaction Potential Assessment tool," Comput. Human Behav., vol. 87, pp. 308-316, 2018.

[30] C.-C. (Brian) Chen, "Gamify online courses with tools Built into your learning management system (LMS) to enhance self-determined and active learning," Online Learn., vol. 22, no. 3, pp. 41-54, 2018.

[31] L. De-Marcos, A. Domínguez, J. Saenz-De-Navarrete, and C. Pagés, "An empirical study comparing gamification and social networking on e-learning," Comput. Educ., vol. 75, pp. 82-91, 2014. 